\title{
A educação em saúde como uma estratégia na prevenção da sífilis na Atenção
}

\section{Primária a Saúde}

\author{
Health education as a strategy for the prevention of syphilis in Primary Health Care \\ La educación para la salud como estrategia de prevención de la sífilis en la Atención Primaria de
}

Salud

Amanda Guimarães Cunha ORCID: https://orcid.org/0000-0002-0893-3281

Centro Universitário Fibra, Brasil

E-mail: amandaguic18@gmail.com

Ana Karina Rodrigues Coelho

ORCID: https://orcid.org/0000-0001-8504-689X Centro Universitário Fibra, Brasil

E-mail: anna.karinna1999@gmail.com

Iodete Cardoso de Souza

ORCID: https://orcid.org/0000-0001-9084-1046

Escola Superior da Amazônia, Brasil

E-mail: souzaiodete7@gmail.com

Bianca Brabo de Leão

ORCID: https://orcid.org/0000-0001-8930-9394

Centro Universitário Fibra, Brasil

E-mail: brabodeleao.bianca@hotmail.com

Ísis Martins Guedes

ORCID: https://orcid.org/0000-0003-4458-4274

Faculdade Estácio de Macapá, Brasil

E-mail: isismguedes@gmail.com

Diego Martins Coelho

ORCID: https://orcid.org/0000-0003-3928-3055

Faculdade Estácio de Macapá, Brasil

E-mail: enfdiegocoelho@gmail.com

Maria Eduarda Monteiro Pereira ORCID: https://orcid.org/0000-0002-3679-9120

Centro Universitário do Estado do Pará, Brasil

E-mail: mariamontpereira@outlook.com

Manuelle Pinto Sotero

ORCID: https://orcid.org/0000-0002-6798-4572

Centro Universitário do Estado do Pará, Brasil

E-mail: adv.manuelle@gmail.com

Maria Clara Arêa Leão Martins

ORCID: https://orcid.org/0000-0002-9804-7717

Centro Universitário do Estado do Pará, Brasil

E-mail: arealeaomartins.mariaclara@gmail.com

Natalia Carvalho Aguiar

ORCID: https://orcid.org/0000-0002-5174-8014

Centro Universitário Fibra, Brasil

E-mail: nataliacarvalhoag@gmail.com

Débora Hosana Biasi

ORCID: https://orcid.org/0000-0003-0079-3963

Centro Universitário do Estado do Pará, Brasil

E-mail: Deborabiasi7@gmail.com

Arthur Andrade Magalhães

ORCID: https://orcid.org/0000-0001-5211-2045

Centro Universitário do Estado do Pará, Brasil

E-mail: arthurandrade16@icloud.com

Jessica Luiza Lima Santos

ORCID: https://orcid.org/0000-0002-8180-0995

Universidade da Amazônia, Brasil

E-mail: jessicaluiza79@gmail.com 


\author{
Amanda Almeida Vieira \\ ORCID: https://orcid.org/0000-0003-2211-0115 \\ Centro Universitário do Estado do Pará, Brasil \\ E-mail: amandaav2000@gmail.com \\ João de Souza Mendonça \\ ORCID: https://orcid.org/0000-0002-2204-5010 \\ Universidade da Amazônia, Brasil \\ E-mail: joaosm.farmaco@gmail.com
}

\begin{abstract}
Resumo
A sífilis é uma infecção bacteriana de caráter sistêmico, ocasionada através do Treponema pallidum, uma bactéria espiroqueta e gram-negativa, curável e exclusiva do ser humano, entretanto quando o tratamento não é realizado em tempo oportuno, pode resultar em uma evolução crônica com danos de potencial irreversível. Destarte, o objetivo deste estudo é descrever o desempenho da enfermagem, com auxílio da equipe multiprofissional, utilizando-se da atividade de educação em saúde como estratégia de conscientização e prevenção da sífilis. Trata-se de um relato de relato de experiência, de caráter descritivo, com abordagem qualitativa, realizado em uma Unidade Municipal de Saúde (UMS) de Ananindeua. Conforme a experiência, foi possível observar, diante da interação, a primordialidade de informações em relação a sífilis, de modo que a educação em saúde é fundamental para o acesso ao conhecimento, acerca das doenças e demonstrou na prática como pode-se ajudar a população a se prevenir e manter os cuidados necessários perante a doença. Com base nas ações prestadas, fica evidente e se faz necessário observar a necessidade de promoção de ações direcionadas ao controle da doença, incluindo ações de prevenção e notificação, busca ativa e tratamento adequado.
\end{abstract}

Palavras-chave: Sífilis; Atenção Primária à Saúde; Educação em saúde.

\begin{abstract}
Syphilis is a systemic bacterial infection caused by Treponema pallidum, a spirochete and gram-negative bacterium, curable and exclusive to humans, however when treatment is not carried out in a timely manner, it can result in a chronic course with damage of irreversible potential. Thus, the objective of this study is to describe the performance of nursing, with the help of the multidisciplinary team, using the health education activity as a syphilis awareness and prevention strategy. This is a descriptive experience report, with a qualitative approach, carried out in a Municipal Health Unit in Ananindeua. According to experience, it was possible to observe, given the interaction, the primordiality of information in relation to syphilis, so that health education is essential for access to knowledge about diseases and demonstrated in practice how you can help the population to prevent and maintain the necessary care before the disease. Based on the actions provided, it is clear and necessary to observe the need to promote actions aimed at controlling the disease, including prevention and notification actions, active search and appropriate treatment. Keywords: Syphilis; Primary Health Care; Health education.
\end{abstract}

\title{
Resumen
}

La sífilis es una infección bacteriana sistémica causada por Treponema pallidum, una espiroqueta y bacteria gramnegativa, curable y exclusiva de los humanos, sin embargo cuando el tratamiento no se realiza de manera oportuna puede resultar en un curso crónico con daño de potencial irreversible. Así, el objetivo de este estudio es describir el desempeño de la enfermería, con la ayuda del equipo multidisciplinario, utilizando la actividad de educación en salud como estrategia de sensibilización y prevención de la sífilis. Se trata de un relato de experiencia descriptiva, con enfoque cualitativo, realizado en una Unidad Municipal de Salud en Ananindeua. Según la experiencia, se pudo observar, dada la interacción, la primordialidad de la información en relación a la sífilis, por lo que la educación en salud es fundamental para el acceso al conocimiento sobre las enfermedades y demostró en la práctica cómo ayudar a la población a prevenir y mantener los conocimientos necesarios. cuidado antes de la enfermedad. A partir de las acciones previstas, es claro y necesario observar la necesidad de impulsar acciones encaminadas al control de la enfermedad, incluyendo acciones de prevención y notificación, búsqueda activa y tratamiento adecuado.

Palabras clave: Sífilis; Primeros auxilios; Educación para la salud.

\section{Introdução}

A sífilis é uma infecção bacteriana de caráter sistêmico, ocasionada através do Treponema pallidum, uma bactéria espiroqueta e gram-negativa, curável e exclusiva do ser humano, entretanto quando o tratamento não é realizado em tempo oportuno, pode resultar em uma evolução crônica com danos de potencial irreversível (Júnior, 2016).

A doença pode ser transmitida por contato sexual, chamada sífilis adquirida, e via vertical, chamada sífilis congênita, 
que acontece por via transplacentária em qualquer momento durante a gravidez ou no parto, após contato do recém-nascido (RN) com lesões maternas. Possui formas características de manifestação, geralmente caracterizada em três fases, sendo a primária, secundária e terciária e a congênita por sintomatologia mais característica (Toledo et al.,2013).

$\mathrm{Na}$ infecção os treponemas penetram diretamente nas membranas mucosas ou entram por abrasões da pele. A transmissão é maior nos estágios iniciais (sífilis primária e secundária) da infecção, diminuindo gradativamente com o tempo (Peeling et al., 2017).

Ademais, pode afetar qualquer órgão do corpo e sem o tratamento adequado pode resultar em problemas neurológicos, cardiovasculares ou ósseos. A sífilis foi uma doença bastante presente na sociedade, mas com a introdução da penicilina e das campanhas de prevenção, a doença sofreu um declínio de sua prevalência e incidência (Souza, 2017).

Atualmente o Sistema Único de Saúde (SUS) tem como um dos grandes desafios a diminuição de ocorrências de Infecções Sexualmente Transmissíveis (IST) no país, principalmente a sífilis. Nos países desenvolvidos, a sífilis é uma das principais infecções transmitida pelo o ato sexual desprotegido com maior magnitude e transcendência no mundo. A população com faixa etária dentre 15 e 30 anos, considerada a população jovem é mais afetada por serem sexualmente ativos (Rodrigues et al., 2016).

Portanto, a Atenção Primária em Saúde tem grande importância na assistência aos portadores de sífilis, na prevenção e no manejo da infecção, por meio de projetos de conscientização, intervenção, detecção de situações e fatores de risco, colaborando para o diagnóstico precoce, adesão ao tratamento efetivo do paciente e seu parceiro sexual, e na comunidade promovendo educação em saúde (Moreira et al., 2020).

Tendo em vista que os enfermeiros possuem maior vínculo com a comunidade e por serem veículos de informação na atenção primária, o conhecimento destes acerca do manejo desta doença pode corroborar para um desfecho favorável, contribuindo na elaboração de estratégias que apontem caminhos para uma assistência de qualidade (Rodrigues et al., 2016).

Ademais, a prevenção dessa infecção se tornou um grande desafio para a saúde pública, principalmente em facilitar o acesso da população vulnerável, disponibilizar assistência eficaz, e assim permitir a diminuição dos índices dessa patologia. A integração da população com as atividades desenvolvidas nas Unidades Básicas de Saúde permitirá entender melhor os problemas, com a construção de novas e melhores formas de intervenção fortalecendo, deste modo, a Atenção Primária em Saúde (Moreira et al., 2020).

E para isso, utiliza-se a Educação em Saúde como ferramenta de atuação por ser uma prática social, cujo processo contribui para a formação da consciência crítica das pessoas a respeito de seus problemas de saúde, a partir da sua realidade, e estimula a busca de soluções e organização para a ação individual e coletiva (Brasil, 2007).

Destarte, o objetivo deste estudo é descrever o desempenho da equipe multiprofissional utilizando-se da atividade de educação em saúde como estratégia de conscientização e prevenção da sífilis.

\section{Metodologia}

Trata-se de um relato de relato de experiência, de caráter descritivo, com abordagem qualitativa, realizado em uma Unidade Municipal de Saúde (UMS) de Ananindeua, esta que conta com atendimentos de diversas especialidades, ofertando serviços de saúde à população do bairro que está inserido. A atividade ocorreu no primeiro semestre do ano de 2021, a partir do estágio supervisionado de acadêmicos da área da saúde de diversas Instituições de Ensino Superior (IES) da região metropolitana da cidade de Belém no Pará.

Destaca-se que este tipo de metodologia é uma produção que valoriza o cultivo de conhecimentos, no qual o autor realiza a elaboração e reinscrição do tema através da memória, onde o sujeito constrói seus direcionamentos de pesquisa ao 
longo da evolução dos diferentes propósitos. Assim, enquadra-se como uma narrativa científica capaz de englobar produções e processos de caráter subjetivos. Esta caracteriza-se também por uma pluralidade de bases teóricas e metodológicas, valorizando o sentido descritivo e interpretativo circunscrito em um determinado tempo histórico (Daltro \& Faria, 2019).

A experiência transcorreu na sala de espera central da UMS e contou com os pacientes que aguardavam pelas consultas. Primeiramente, a atividade iniciou-se a partir de uma palestra com auxílio de um folder, na qual enfatizou-se principalmente a prevenção da sífilis, além de abordar os principais tópicos acerca da doença. A função da explicação oral era de informar os pacientes sobre o tema, para que assim pudessem participar da dinâmica "verdadeiro x falso".

Posteriormente, distribuiu-se plaquinhas que consistiam em um lado verde e outro vermelho e sorteou-se algumas afirmações para que assim se iniciasse a dinâmica, a qual seguia os seguintes passos: sorteou-se as afirmações, lia-se uma destas e perguntava-se se aquela afirmação era verdadeira ou falsa, assim os pacientes respondiam com o lado da plaquinha que achavam ser correspondente à pergunta, a partir disso, iniciava-se uma roda de conversa diante da explicação dos acadêmicos.

A fundamentação teórica perpassou pela busca bibliográfica em bases de dados científicas digitais, sendo elas: Scientific Electronic Library Online (SCIELO), Literatura Latino-Americana e do Caribe em Ciências da Saúde (LILACS), Biblioteca Virtual em Saúde (BVS) com a utilização de palavras-chaves colhidas nos Descritores em Ciências da Saúde (DeCS), sendo elas: "Sífilis"; “Atenção Primária à Saúde"; "Enfermagem”. Esta etapa visou fundamentar e promover maior conhecimento científico aos acadêmicos e relevância ao estudo.

As atividades contaram com a participação de dezoito usuários da unidade, sendo que o público presente era diverso, sendo os presentes jovens, adultos, idosos e gestantes. Para dar suporte às atividades, houve a participação de uma enfermeira da unidade de saúde.

\section{Resultados e Discussão}

Conforme foi possível observar na ação, e por diante na interação, há a necessidade de conscientizar e educar a população acerca das ISTs, com ênfase na sífilis, de modo que se tem conhecimento popular sobre o assunto, nos âmbitos de prevenção e tratamento, mas pouco se põe em prática, como também é relevante salientar a primordialidade de informações de fácil compreensão em relação a doença, desse modo que a educação em saúde se mostra fundamental para o acesso ao entendimento acerca das doenças e demonstrou na prática como pode-se ajudar a população a conhecer, se prevenir e manter os cuidados necessários perante a doença.

De acordo com o Boletim Epidemiológico de Sífilis, em 2019 foram notificados 152.915 casos de sífilis adquirida em todo o país, com taxa de detecção de 72,8 casos por 100 mil habitantes. A maior parte das notificações ocorreu em indivíduos entre 20 e 29 anos (36,2\%). Houve redução de 4,5\% na taxa de deteç̧ão nacional em relação a 2018, que apresentou taxa de 76,2 por 100 mil habitantes. Em gestantes, foram 61.127 casos em 2019, com redução de 3,3\% em relação ao ano anterior (63.182 casos) (Ministério da Saúde, 2020).

A Educação em Saúde é uma estratégia que potencializa o cuidado de enfermagem ao envolver atividades educativas na assistência ao paciente, utilizando recursos disponíveis nos serviços de saúde, sejam públicos ou privados. Sendo, estas ações importantes para a promoção da qualidade de vida e para o desenvolvimento de tarefas diárias das pessoas (Vieira et al., 2017).

Portanto, o objetivo dessas ações em saúde é fornecer orientações, além de esclarecer dúvidas, prevenir doenças e/ou promover adaptação a atual condição de saúde do paciente, contribuindo para o autocuidado e para a qualidade de vida. Para tornar isso possível, o enfermeiro pode lançar mão de diversos recursos didáticos e tecnológicos, fundamentando-se em 
conhecimento científico para troca de informações com o paciente e/ou familiar durante a consulta de enfermagem ou em palestras organizadas com utilização de recursos audiovisuais (Dalmolin et al., 2016).

Dessa maneira, as práticas de educação em saúde envolvem segmentos que valorizam a prevenção e promoção tanto quanto as práticas curativas, de forma a ajudar a população que necessita construir seus conhecimentos e aumentar sua autonomia nos cuidados individuais e coletivamente. (Falkenberg et al., 2014).

A princípio, percebeu-se que a maioria do público em questão encontrava-se tímido e desatento, tendo em vista que havia transição constante de pessoas no momento da palestra, o que a curto prazo cessou, dessa forma, a equipe de acadêmicos iniciou um processo de acolhimento e apresentação, explicando o objetivo da ação e a importância da participação do público.

Logo após, realizou-se uma explanação acerca da patologia, em linguagem acessível, na qual foi evidenciado os principais aspectos que envolvem a doença, assim como o seu curso. Neste momento, utilizou-se do material abrangido no folder, para que os pacientes acompanhassem a fala dos discentes e levassem este material como um lembrete.

Como resultado da palestra e início da dinâmica e por consequência a roda de conversa, os usuários se mostraram entusiasmados com a interação descontraída, onde perguntaram sobre imunidade contra sífilis, se quando gestante, a mulher transmitiria a doença ao bebê, os malefícios ao bebê, relataram sobre a dor do medicamento usado no tratamento da doença, questionaram sobre o diagnóstico e se o mesmo poderia ser realizado na UMS, e por fim, relataram alguns casos de pessoas próximas com a doença.

Logo, explicou-se que o uso correto e regular da camisinha feminina ou masculina é uma medida importante de prevenção da sífilis. O acompanhamento das gestantes e parcerias sexuais durante o pré-natal de qualidade contribui para o controle da sífilis congênita. Importante destacar que a sífilis não confere imunidade permanente, ou seja, mesmo após o tratamento adequado, cada vez que entrar em contato com o agente etiológico (T. pallidum) a pessoa pode ter a doença novamente.

Outro ponto importante, foi sobre a sífilis congênita que é um agravo evitável, desde que a sífilis gestacional seja diagnosticada e tratada oportunamente. Entretanto, apesar dos esforços, ainda permanece como grave problema de saúde pública e evidencia lacunas especialmente na assistência pré-natal. A maior parte dos casos de sífilis congênita é decorrente de falhas na testagem durante o pré-natal, ou de tratamento inadequado ou ausente da sífilis materna (Lago et al., 2013).

Portanto, essas falhas são o resultado da disseminação hematogênica do Treponema pallidum da gestante infectada não tratada ou inadequadamente tratada para o seu concepto, geralmente por via transplacentária, independentemente da idade gestacional. Eventualmente, essa transmissão pode ocorrer durante o nascimento, por contato direto com lesões de sífilis no canal de parto (Ministério da Saúde, 2020). A triagem sorológica no pré-natal é uma medida eficaz e o tratamento com penicilina é efetivo, barato e facilmente disponível no SUS (Nonato et al., 2015).

Segundo o Ministério da saúde, o tratamento da sífilis primária indica-se penicilina benzatina 2.4 milhões UI, intramuscular (IM) em dose única. Na sífilis secundária e latente, prescreve-se penicilina benzatina 2,4 milhões, IM que deve ser repetida após 1 semana, totalizando 4,8 milhões. Já na sífilis tardia, é prescrito penicilina benzatina 2,4 milhões UI, IM, semanal, durante 3 semanas totalizando 7,2 milhões de UI (Ministério da Saúde, 2015).

Quanto ao diagnóstico laboratorial da sífilis e a escolha de exames laboratoriais mais adequados, deverão considerar a fase evolutiva da doença. Dentre os testes, temos o teste rápido (TR) e o VDRL, com reaginas plasmáticas, são testes sensíveis, simples e baratos, sendo os resultados apresentados de duas formas, um na forma qualitativa (reagente, não reagente, no limite) e quantitativa (positivo 1:16) (Cavalcante et al., 2012).

Baseado na experiência vivenciada pela equipe, evidenciou-se nesse estudo que haviam muitas dúvidas relacionadas ao tema que surgiram no decorrer dos questionamentos da dinâmica, principalmente sobre diagnóstico, tratamento e prevenção da doença, bem como em especifico relacionando a sífilis e a gestação, por conseguinte perante este espaço, conseguiu-se 
esclarecer os questionamentos dos usuários, o que de certa forma, foi essencial para que a palestra fosse repassada de uma maneira clara e objetiva.

Além dos esclarecimentos e informação acerca do tema, durante a roda de conversa observou-se que as pessoas tinham um conhecimento básico sobre a sífilis, mas era necessário o alerta sobre os sinais e sintomas, o uso de preservativos e os agravos a curto e longo prazo que poderia ser acarretado se não houvesse a procura de ajuda da equipe de saúde.

Por fim, houve a finalização das atividades, na qual se ratificou a relevância da prevenção à doença, com o uso de preservativos, bem como orientou-se as gestantes a fazerem o acompanhamento ao pré-natal como também realizar os exames solicitados nas consultas, assim como houve agradecimentos por parte dos pacientes aos discentes pela iniciativa e pela abordagem mais práticas. Outrossim, muitos pacientes reiteraram a importância dessas atividades para a promoção da saúde individual e coletivo.

Todavia, enfatiza-se a relevância da atuação do enfermeiro juntamente com a equipe multiprofissional na realização de ações educativas como a descrita nesse estudo, posto que essas, pelo contato real e contínuo com a comunidade, podem propiciar a obtenção e aprimoramento de habilidades e competências necessárias ao exercício da profissão. Dessa forma, também reitera-se a importância da inserção do acadêmico neste cenário, uma vez que esses apresentam papel fundamental na promoção da saúde e, através do contato com a realidade fora do ambiente acadêmico, podem desenvolver estratégias para a melhora no campo assistencial, embasado em um olhar holístico e acolhedor (Silva et al., 2020).

\section{Conclusão}

Com base nas ações prestadas, fica evidente e se faz necessário observar a necessidade de promoção de ações direcionadas ao controle da doença, incluindo ações de prevenção e notificação, busca ativa e tratamento adequado, para assim compreender a importância de uma rede de assistência integral, a fim de garantir um apoio para esses pacientes, visto que por conta de diversos fatores, muitos usuários não procuram assistência médica para resolver o problema adequadamente.

Como meio de prevenção primária, foram citadas as ações de educação em saúde, por meio de rodas de conversa em salas de espera, embora seja uma maneira de repassar informações de forma simples é um método que que valoriza os saberes, o conhecimento prévio da população e não somente o conhecimento científico.

Como fator limitante do estudo, considera-se a escassez desse tipo de ação sobre infecções sexualmente transmissíveis, como a sífilis, no município de Ananindeua, tendo em vista a incidência e reincidência destes tipos de doenças é recorrente.

Em síntese, evidenciou-se a partir dos resultados obtidos que o objetivo foi alcançado, posto que houve grande interação e reflexão a respeito da temática, o que permitiu aos usuários desenvolver a sua autonomia e emancipação como sujeito histórico e social, capaz de opinar nas decisões de saúde para cuidar de si, de sua família e de sua coletividade.

\section{Referências}

Cavalcante, A. E. S., Silva, M. A. M., Rodrigues, A. R. M., Netto, J. J. M., Moreira, A. C., \& Goyanna, N. F. (2012). Diagnóstico e Tratamento da Sífilis: Uma Investigação com Mulheres Assistidas na Atenção Básica em Sobral, Ceará. J bras Doenças Sex Transm, 24 (4), $239-245$.

Dalmolin, A., Girardon-Perlini, N. M. O., Coppetti, L. C., Rossato, G. C., Gomes, J. S., \& Silva, M. E. N. (2016). Vídeo educativo como recurso para educação em saúde a pessoas com colostomia e familiares. Rev Gaúcha Enferm. 37(esp):e68373.

Daltro, M. R., \& Faria, A. A. Relato de experiência: Uma narrativa científica na pós-modernidade. (2019). Estudos e Pesquisas em Psicologia, 19(1), 223237.

Falkenberg, M. B., Mendes, T. d. P. L., Moraes, E. P. d., \& Souza, E. M. (2014). Educação em saúde e educação na saúde: conceitos e fundamentais para uma saúde coletiva. Ciênc. saúde coletiva, 3 (19). 
Research, Society and Development, v. 10, n. 14, e22101421525, 2021

(CC BY 4.0) | ISSN 2525-3409 | DOI: http://dx.doi.org/10.33448/rsd-v10i14.21525

Gomez, G. B., Kamb, M. L., Newman, L. M., Mark, J., Broutet, N., \& Hawkes, S. J. Untreated maternal syphilis and adverse outcomes of pregnancy: a systematic review and meta-analysis. Bull World Health Organ. 2013. 15;91(3):217-26. Disponível em: https://doi.org/10.2471/BLT.12.107623

Júnior, O. F. C. B. (2016). Prevenção da sífilis congênita em uma unidade básica de saúde de são luís - MA [Curso de Especialização em Atenção Básica em Saúde, Universidade Federal do Maranhão/UNASUS]. https://ares.unasus.gov.br/acervo/html/ARES/8835/1/OLINTO\%20FARIAS\%20CAST ELO\%20BRANCO\%20JUNIOR.pdf

Lago, E. G., Vaccari, A., \& Fiori, R. M. Clinical features and follow-up of congenital syphilis. Sex Transm Dis. (2013). 40(2):85-94. Available from: https://doi.org/10.1097/olq.0b013e31827bd688

Ministério da Saúde. (2021). Infecções sexualmente transmissíveis: Sífilis. http://www.aids.gov.br/pt-br/publico-geral/infeccoes-sexualmentetransmissiveis/sifilis

Ministério da Saúde. Sífilis. (2011). https://bvsms.saude.gov.br/bvs/publicacoes/sifilis_estrategia_diagnostico_brasil.pdf.

Ministério da Saúde. (2015). Protocolo Clínico e Diretrizes Terapêuticas (PCDT). https://bvsms.saude.gov.br/bvs/publicacoes/ protocolo_clinico_diretrizes_terapeutica_atencao_integral_pessoas_infeccoes_sexualmente_transmissiveis.pdf

Ministério da Saúde. (2020). Brasil avança no enfrentamento à sífilis. http://www.aids.gov.br/pt-br/noticias/brasil-avanca-no-enfrentamento-sifilis.

Ministério da Saúde. (2020). Departamento de Doenças de Condições Crônicas e Infecções Sexualmente Transmissíveis. Protocolo clínico e diretrizes terapêuticas para atenção integral às pessoas com infecções sexualmente transmissíveis (IST). http://www.aids.gov.br/pt-br/pub/2015/protocolo-clinico-ediretrizes-terapeuticas-para-atencao-integral-pessoas-com-infeccoes

Moreira, B. C., Ribeiro, J. L., Figueredo, R. C. d., Amorim, R. C. C. d. S., Silva, L. S., \& Silva, R. S. (2020). Os principais desafios e potencialidades não enfrentamento da sífilis pela atenção primária em saúde. Revista Multidisciplinar de Estudos Científicos em Saúde, 5 (9), 3 -13.

Nonato, S. M., Melo, A. P. S., \& Guimarães, M. D. C. (2015). Sífilis na gestação e fatores associados à sífilis congênita em Belo Horizonte-MG, 20102013. Epidemiol. Serv. Saúde, 24 (4), 681-694.

Peeling, R. W., Mabey, D., Kamb, M. L., Chen, X-S., Radolf, J. D., \&Benzaken, A. S. (2017). Syphilis. Nat Rev Dis Prim. $29(3)$, 17073.

Silva, J. M. L., Monteiro, A. J. C., Coutinho, E. S., Cruz, L. B. S., Araújo, L. T., Dias, W. B., \& Costa, P. V. D. P. (2020). O brinquedo terapêutico instrucional como ferramenta na assistência oncológica infantil. Research, Society and Development, 9 (7): 1-14, e408974253.

Souza, B. C. d. (2017). Manifestações clínicas orais da sífilis. RFO, Passo Fundo, 22 (1), 82-85.

Toledo, H. S., Peverar, J., \& Bonafé, S. M. (2013). Manifestações clínicas da sífilis adquirida e congênita, diagnóstico e tratamento. VIII EPCC, 1(1), 1-4.

Vieira, F. S., Portela, N. L. C., Sousa, G. C., Costa, E. S., Oliveira, D. E. P., \& Neiva, M. J. L. M. (2017). Inter-relação das ações de educação em saúde no contexto da Estratégia Saúde da Família: percepções do enfermeiro. Rev Fund Care Online , 9(4):1139-44. 